\title{
CRÍA DE ANUROS EN \\ LA LAGUNA DE CHOZAS DE ARRIBA (LEÓN) EN 1980
}

\author{
por \\ Jerónimo Alvarez ${ }^{1}$ y Alfredo Salvador ${ }^{1}$
}

\section{SUMMARY}

Reproductive patterns of anurans in a León pond located near Chozas de Arriba were studied during 1980. Breeding and larval periods for five species are discussed. The breeding sequence was as follows:B ufo calamita, Pelobates cultripes, Hyla arborea and Rana perezi. Wintering larvae of $R$. perezi were collected in November.

\section{RESUMEN}

Se estudian en este trabajo los ciclos de cría de anuros en una laguna de León durante 1980. La secuencia de especies que se encontró es primero, $B$. calamita y $P$. cultripes, y después Hyla arborea y $R$. perezi. Se sugiere como tiene lugar el reparto de recursos en la comunidad de cría. Se han encontrado larvas invernales de $R$. perezi en Noviembre.

\section{INTRODUCCION}

Son escasos los trabajos dedicados a la biología de los anuros ibéricos y se puede decir que, en general, son poco conocidos los ciclos biológicos de las distintas especies de la península ibérica. Es nuestro propósito en centrar este estudio en una comunidad de cría determinada, examinando el reparto que hacen las distintas especies de la laguna para su cría y de paso contribuir al mejor conocimiento de la biología de nuestros anfibios.

\section{MATERIAL Y METODO}

Se ha elegido la laguna situada junto a Chozas de Arriba (30TTN7812), a unos 890 metros s.n.m. El estudio se ha realizado exclusivamente durante el año 1980. A lo largo de él se han efectuado

(1) Departamento de Zoología, Facultad de Biología, Universidad de León. 
una serie de visitas, de las que se han obtenido diversas observaciones que se incluyen en el texto. También se han obtenido muestras de renacuajos mediante sacadera en las siguientes fechas:

$\begin{array}{rrrrrr}\text { Muestreo } & 1 . & 24 \text { de Febrero } & \text { Muestreo } 11 . & 1 \text { de Mayo } \\ \text { Muestreo } & 2 . & 1 \text { de Marzo } & \text { Muestreo } 12 . & 10 \text { de Mayo } \\ \text { Muestreo } & \text { 3. } & 7 \text { de Marzo } & \text { Muestreo } 13 . & 27 \text { de Mayo } \\ \text { Muestreo } & \text { 4. } & 12 \text { de Marzo } & \text { Muestreo } 14 . & 19 \text { de Junio } \\ \text { Muestreo } & 5 . & 15 \text { de Marzo } & \text { Muestreo } 15 . & 9 \text { de Julio } \\ \text { Muestreo } & 6 . & 28 \text { de Marzo } & \text { Muestreo } 16 . & 18 \text { de Julio } \\ \text { Muestreo } & 7 . & 5 \text { de Abril } & \text { Muestreo } 17 . & 30 \text { de Julio } \\ \text { Muestreo } & 8 . & 12 \text { de Abril } & \text { Muestreo } 18 . & 29 \text { de Agosto } \\ \text { Muestreo } & 9 . & 22 \text { de Abril } & \text { Muestreo } 19 . & 26 \text { de Septiembre } \\ \text { Muestreo } & 10 . & 26 \text { de Abril } & & & \end{array}$

Las muestras se han almacenado permanentemente en formol al $10 \%$. En el laboratorio se ha procedido a su identificación y posterior medición. para su identificación se han utilizado las claves de Boulenger (1896-1897) y los ejemplares han sido examinados mediante microscopio binocular. A cada ejemplar se le ha tomado la fórmula labial y se ha medido la longitud de cabeza y cuerpo $(\mathrm{CC})$ desde el extremo del hocico hasta la cloaca, y la longitud total (LT) hasta el extremo de la cola. Para ello se ha utilizado un calibre. Los resultados se expresan siempre en milímetros. A cada ejemplar se le ha asignado un estadio de crecimiento de acuerdo con la tabla de Gossner (1960).

En total se han podido estudiar cuatro especies de anuros: Bufo calamita, Pelobates cultripes, Hyla arborea y Rana perezi.

\section{RESULTADOS}

\section{Vegetación}

La laguna se halla dividida en tres sectores. Alrededor del mayor de ellos se ha construído un muro de contención del agua. El sector mayor es permanente y los otros dos son temporales, llegándose a secar en el verano según los años.

Con respecto a la vegetación se puede reconocer en general desde el agua libre hasta la orilla el tipo de sucesión que se describe a continuación: 
- Comunidades que ocupan la zona infralitoral constantemente inundada, formada por plantas hidrófitas enraizadas o no al sustrato del fondo, intraacuáticas o con hojas superiores flotantes, y que en general se incluyen en la clase Potametea.

- Comunidades formadas fundamentalmente por especies que colonizan los bordes de laguna y que constituyen los cañaverales. Se incluyen en la clase Phragmitetea.

-En la zona supralitoral se reconoce una vegetación terrestre, terofítica, que puede depender de la capa freática, cuyo nivel varía como el de la capa acuática del estanque. Estas comunidades se incluyen fundamentalmente en las clases Molinio-Juncetea e Isoeto-Nano-Juncetea.

El espesor de la capa acuática en el sector grande y mediano permite el establecimiento de comunidades de especies hidrófitas de la clase Potametea (Potamogeton natans, Myriophyllum sp., Ranunculus aquatilis), formando las algas (Chara) un segundo tapiz vegetal por debajo de estas especies, si bien $R$. aquatilis cubre gran parte del sector pequeño. Al disminuir el grado de hidrofilia van apareciendo especies anfibias, helófitas, pertenecientes a la clase Phragmitetea. Sin embargo no podemos hablar de un cañaveral típico, ya que faltan muchas especies características. Sí encontramos Eleocharis palustris que cubre importantes extensiones en los tres sectores, y especies características de Sparganio-Glycerion como son Sparganion erectum, Glyceria flotans y Callictriche sp.

En el borde de la laguna que soporta las variaciones estacionales de nivel se instalan comunidades que se incluyen en tres clases. La clase Littorelletea define las comunidades sumergidas de la orilla que forman pastizales. las especies abundantes son Littorella uniflora y Juncus bulbosus. También hay Juncus heterophyllus, Hydrocotyle vulgaris, Baldellia ranunculoides y Apium inundatum.

Está abundantemente representada la clase Molinio-Juncetea, que define praderas húmedas con un nivel frático elevado, registrándose las siguientes especies: Juncus acutiflorus, Carum verticillatum, Ranunculus repens, Holcus lanatus, Galium palustre, Trifolium repens y Deschampsia caespitosa subsp. refracta. Las considerables variaciones estacionales de nivel permiten el establecimiento de una vegetación terofítica propia de suelos temporalmente encharcados, en invierno y primavera. Se incluye en 
Isoeto-Nano-Juncetea, y entre las especies caracteristicas se encuentran Cicendia filiformis, Juncus pygmaeus, Eryngium viviparum y Mentha pulegium.

\section{SAPO CORREDOR, Bufo calamita.}

El día 1 de Marzo observamos las primeras puestas de sapo Corredor. En 20 de éstas la profundidad media es de $7.2 \mathrm{~cm}$. (3-10). El día 7 de Marzo medimos 26 puestas más y obtenemos $7.4 \mathrm{~cm}$. de profundidad media (5-11), constatando que en esta especie las puestas se efectúan a mucha menor profundidad que en el Sapo de Espuelas. En la visita del 12 de Marzo se obtiene una temperatura del aire a las $15 \mathrm{~h}$. de $14.5^{\circ} \mathrm{C}$ y de $17^{\circ} \mathrm{C}$ en el agua. Las larvas de estas primeras puestas se amontonan ya fuera de la gelatina y están a punto de nacer. Se encuentran en el estadio 18 y miden $4.7 \mathrm{~mm}$. de LT ( 5 ejs.). El 28 de Marzo se comprueba que ha habido puesta masiva de esta especie y se observan tres machos cantando en el agua entre la vegetación entre las 10 y las 13 horas. El día 5 de Abril las larvas de la puesta masiva están ya amontonadas en el exterior de la gelatina. Nuevas puestas de Sapo Corredor se ven el día 20. El día 22 de Abril observamos que los machos comienzan a cantar todavía de día a las $21.15 \mathrm{~h}$. También el 1 de Mayo vemos un macho cantando en la orilla a las $20.15 \mathrm{~h}$. Todavía el 10 de Mayo encontramos 8 puestas de esta especie.

Hemos obtenido renacuajos de esta especie en los muestreos de 5, 12 y 26 de Abril, y 10 y 27 de Mayo. En el muestreo del 5 de Abril aparecen 28 renacuajos que se reparten entre los estadios 30 a 35 (la mayoría se encuentran en los estadios 33 y 34). La LT media en el estadio 33 es de $18.7 \mathrm{~mm}$. (13 ejs.). Del muestreo del 12 de Abril hay 67 larvas, de las que 10 están en el estadio 20 y otras 14 en el 21. Estas últimas miden $2.5 \mathrm{~mm}$. de CC y $6.5 \mathrm{~mm}$. de LT. Se trata en ambos casos de larvas que están a punto de nacer.

En el muestreo del 26 de Abril (Figura 1) obtenemos 25 renacuajos que se incluyen en los estadios 27 a 36 . El 10 de Mayo encontramos una puesta con larvas en el estadio 17. El 27 de Mayo encontramos por un lado unas puestas en estadio 9 y otras en estadio $18,19,20$ y 21 . Además se obtienen 79 renacuajos que pertenecen a los estadios 31 a 43 (Figura 2). Los máximos valores de LT se alcanzan en el estadio 41 , con $10.5 \mathrm{~mm}$. de CC y $24.5 \mathrm{~mm}$. de LT (12 ejs.). A pesar del bajo número de ejemplares se observa disminución de tamaño en los estadios 42 y 43. 


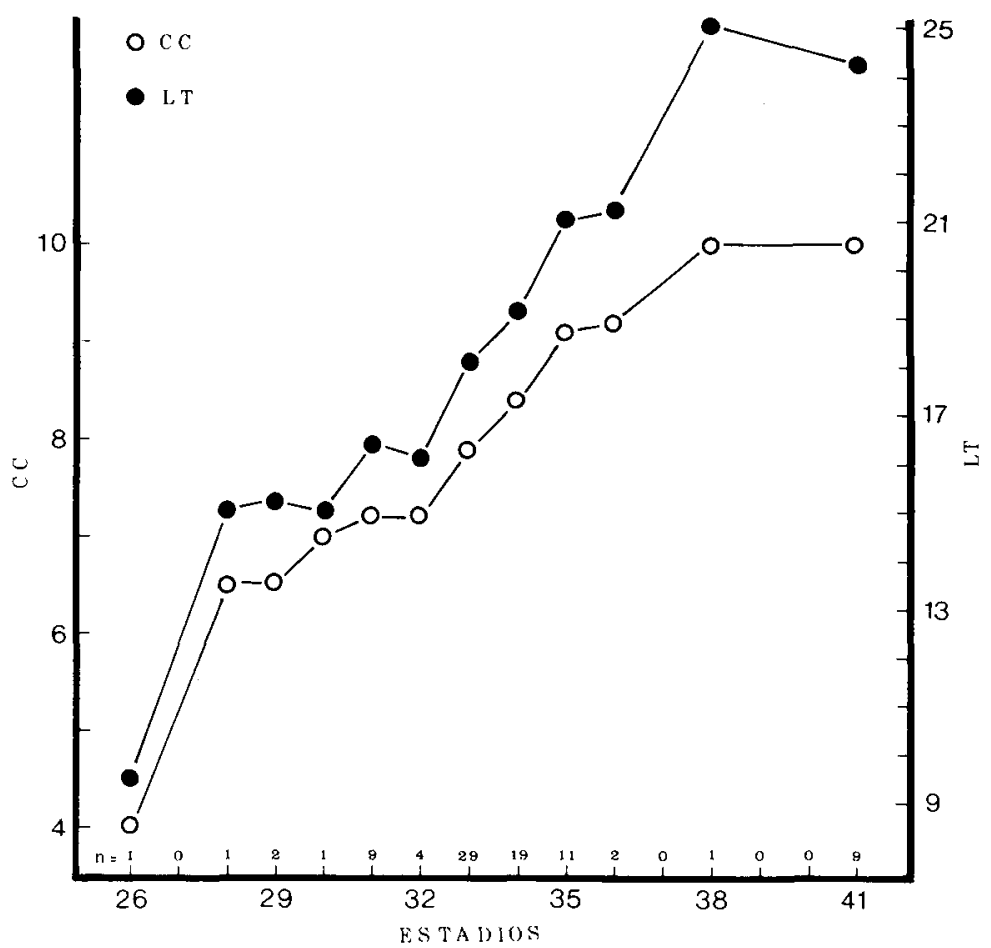

Figura 1.- Sapo Corredor (Bufo calamita). Muestreo del 26 de Abril de 1980. Comparación entre los valores de la longitud de cabeza y cuerpo (CC) y longitud total (LT) en los diferentes estadios. $\mathrm{N}$ representa el número de renacuajos de cada estadio y los círculos los valores medios de los ejemplares de cada estadio.

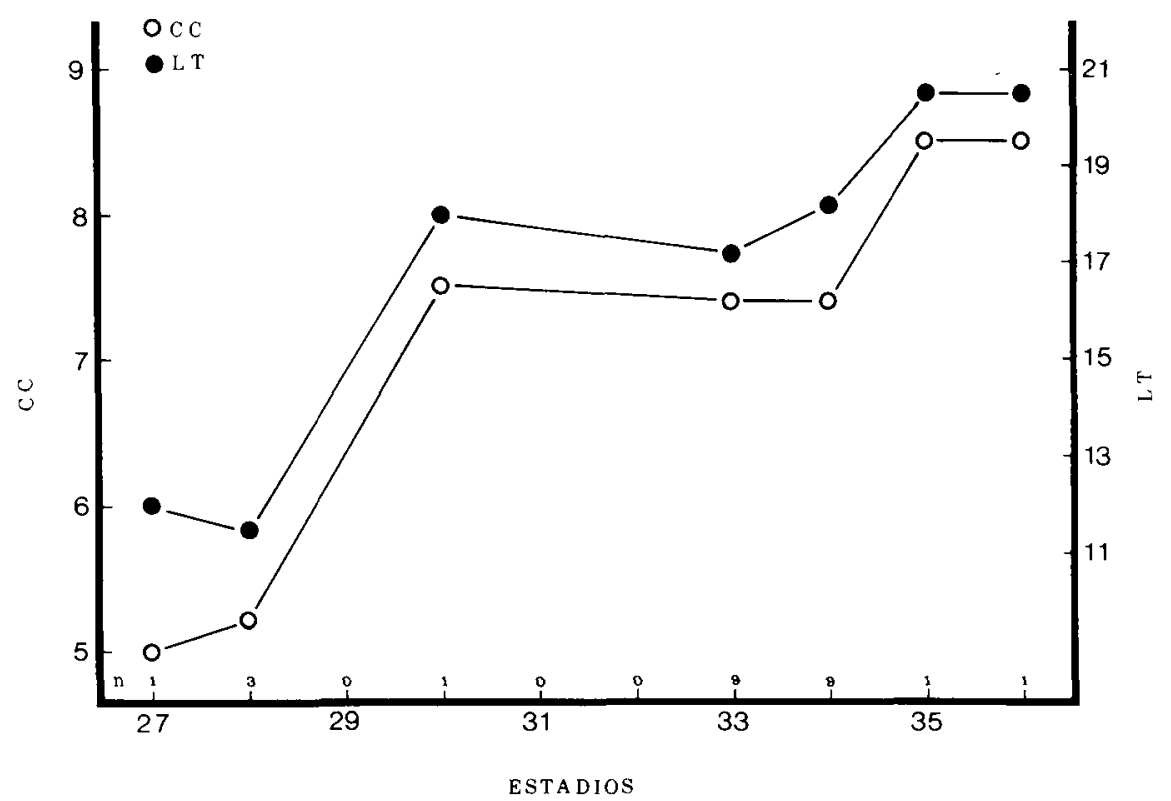

Figura 2.- Sapo Corredor (Bufo calamita). Muestreo del 27 de Mayo de 1980. 
En la visita efectuada el 3 de Junio se observan durante el día abundantes Sapos Corredores recién metamorfoseados en los prados próximos a la laguna, con un tamaño de $9-11.6 \mathrm{~mm}$. de CC. Quedan muy pocos por pasar la metamorfosis.

\section{SAPO DE ESPUELAS, Pelobates cultripes.}

El día 24 de Febrero se encuentran 7 puestas que son las primeras de esta especie. El día 1 de Marzo aparecen numerosas puestas. Se mide la profundidad en 20 de éstas y se obtiene un valor medio de $13.1 \mathrm{cms}$. (9-25 cms.). El 12 de Marzo las larvas están amontonadas fuera de la gelatina y se encuentran en el estadio 18 de Gossner, lo que indica que están a punto de nacer. Para 5 ejemplares se obtiene una LT media de $5.4 \mathrm{~mm}$. El día 15 ya han nacido las larvas y hay además una puesta nueva de esta especie. Todos los renacuajos se reúnen en una zona de algas que no está helada. La LT media que se obtuvo de 12 ejemplares es de $6.9 \mathrm{~mm}$. Posteriormente hemos encontrado puestas aisladas el 22 de Abril y el 10 de Mayo.

Han aparecido renacuajos de esta especie en los muestreos de 5 y 12 de Abril; 1, 10 y 27 de Mayo; 19 de Junio; 9, 18 y 30 de Julio. En el muestreo del 5 de Abril hemos recogido 66 renacuajos de esta especie que se reparten entre los estadios 25 al 28, en su gran mayoría en el 27 (Figura 3). Estos últimos miden $8.6 \mathrm{~mm}$. de CC y $19 \mathrm{~mm}$. de LT. Es de resaltar la gran uniformidad de la muestra en su desarrollo. El 12 de Abril se obtienen 49 renacuajos pertenecientes a los estadios 26 a 28 , que miden en el estadio 26 $7 \mathrm{~mm}$. de CC y $15.8 \mathrm{~mm}$.de LT, valores sensiblemente menores que los del muestreo anterior y que problablemente corresponden a otra puesta. El 1 de Mayo aparecen 16 renacuajos repartidos entre los estadios 26 al 31 (Figura 4). Hay 7 ejemplares en el estadio 27 que miden $10.8 \mathrm{~mm}$. de CC y $24.4 \mathrm{~mm}$. de LT, lo que representa un aumento de tamaño con respecto a renacuajos del mismo estadio de muestreos anteriores. Tenemos 35 renacuajos procedentes del 10 de Mayo que se reparten entre los estadios 26 al 31 , con preferencia entre el 26 y el 28 . Hay 15 ejemplares en el estadio 27 , con $11.5 \mathrm{~mm}$. de CC y $26.5 \mathrm{~mm}$. de LT, que son todavía mayores que los de muestreos anteriores.

El 27 de Mayo (Figura 5) encontramos 53 renacuajos, con rango de desarrollo entre los estadios 26 al 31. Los ejemplares del estadio 27 miden $12.2 \mathrm{~mm}$. de CC y $27.1 \mathrm{~mm}$. de LT. En el muestreo del 19 de Junio apare- 


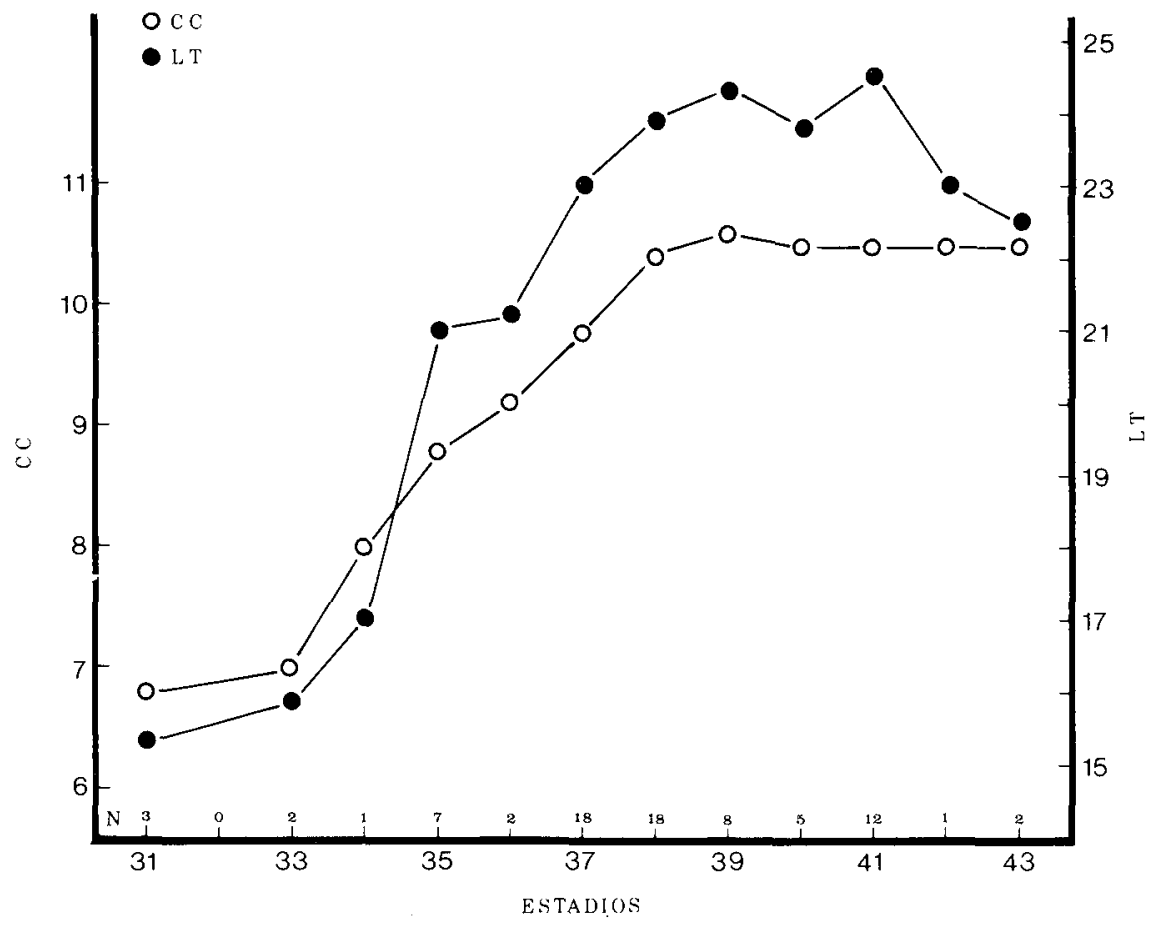

Figura 3.- Sapo de Espuelas (Pelobates cultripes). Muestreo del 5 de Abril de 1980.

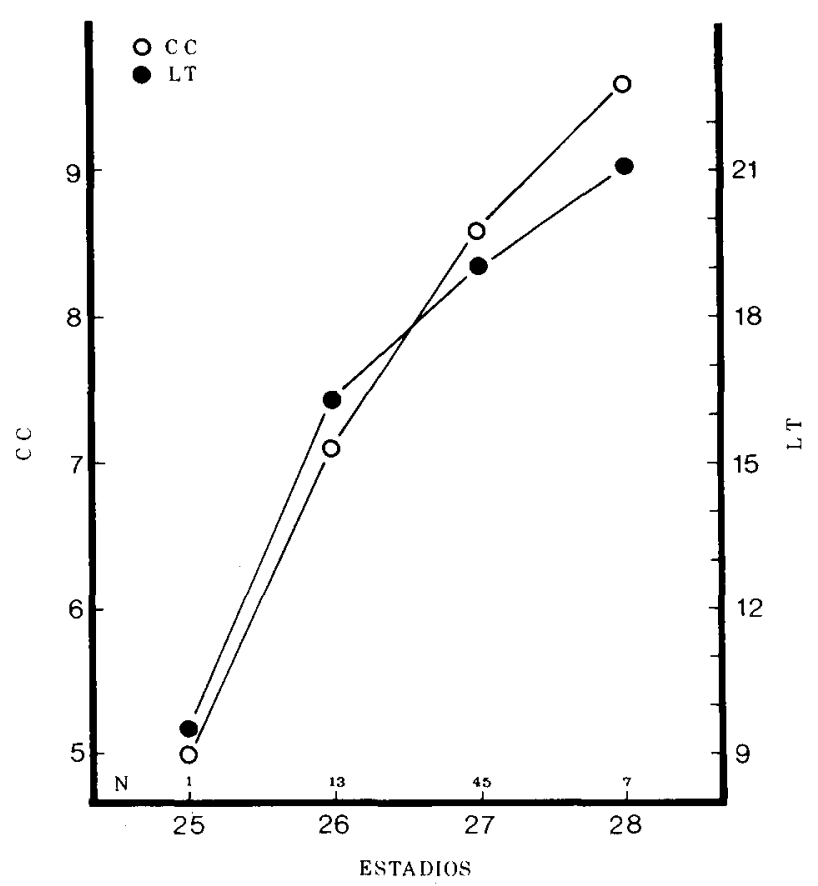

Figura 4.- Sapo de Espuelas (Pelobates cultripes). Muestreo del 1 de Mayo de 1980. 
cen sólamente 11 ejemplares situados entre los estadios 35 a 38 (Figura 6). El mayor tamaño es alcanzado por dos ejemplares del estadio 38 con una LT de $78 \mathrm{~mm}$. y CC respectivas de 37.5 y $38 \mathrm{~mm}$. Del muestreo del 9 de Julio únicamente tenemos 3 renacuajos bastantes retrasados (estadios 26, 27 y 31) que problablemente se correspondan con puestas tardías. Del muestreo del 18 de Julio disponemos sólamente de un renacuajo del estadio 37. El 30 de Julio aparecen 3 renacuajos, de los que dos están en los estadios 35 y 36 . El otro se halla en el estadio 43 y mide $48 \mathrm{~mm}$. de CC y 68 mm. de LT.

\section{RANITA DE SAN ANTONIO, Hyla arborea.}

Durante la visita del 5 de Abril no se observaron adultos ni puestas pero el día 12 ya hay numerosas puestas, con huevos en el estadio 20 de Gossner. El 22 de Abril se observa el primer macho en la orilla a las 21.40 h., oyéndose un gran concierto de machos a las 22.15 h. El 26 de Abril el concierto comienza todavía de día $(21.45 \mathrm{~h}$.), observándose parejas en amplexus a las $23.30 \mathrm{~h}$. Todavía encontramos dos machos en la orilla a las $18.30 \mathrm{~h}$. en la visita del 1 de Mayo.

Se han observado renacuajos de esta especie en los muestreos de 27 de Mayo, 19 de Junio y 9, 18 y 30 de Julio. Del 27 de Mayo tenemos 78 renacuajos, que se reparten entre los estadios 25 a 33 (Figura 7). La mayoría se encuentran en el estadio 27 , con un tamaño medio de $6.1 \mathrm{~mm}$. de CC y $13.1 \mathrm{~mm}$ de LT. En el muestreo del 19 de Junio aparecen 85 renacuajos en estadios 28 al 41 , de los que la mayoría se encuentran en los estadios 31 al 37 . En este último estadio miden $13.2 \mathrm{~mm}$. de CC y $27 \mathrm{~mm}$. de LT (Figura 8).

En el muestreo del 9 de Julio aparecen 29 renacuajos de los estadios 27 al 41, de ellos 12 del estadio 37. Encontramos 21 renacuajos en el muestreo del 18 de Julio (Figura 9). De ellos hay 4 que han tenido la metamorfosis y se hallan en el estadio 46, con $14.1 \mathrm{~mm}$. de CC. En el extremo inferior hay un ejemplar retrasado del estadio 27 y los demás se reparten entre los estadios 36 al 42 . El 30 de Julio se han obtenido 20 ejemplares de los que la mayoría se encuentran en los estadios críticos para la metamorfosis (estadio 40 a 45). En el estadio 40 se alcanza una LT de $33.7 \mathrm{~mm}$. y $\mathrm{CC}$ de $13 \mathrm{~mm}$. En estadios posteriores la CC aumenta hasta alcanzar un valor medio de $14.5 \mathrm{~mm}$. en el estadio 45 (Figura 10). 
Figura 5.- Sapo de Espuelas (Pelobates cultripes). Muestreo del 27 de Mayo de 1980.
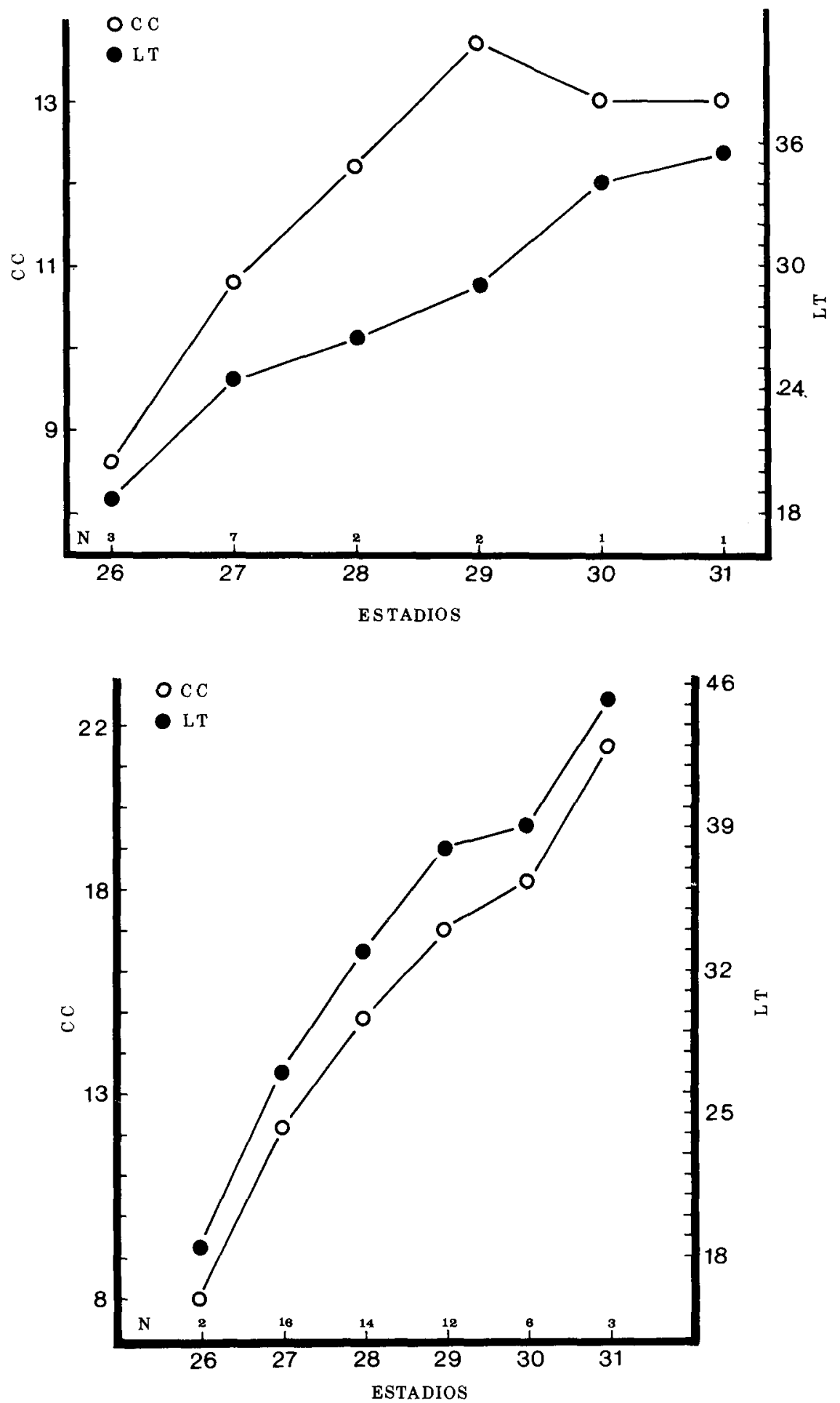

Figura 6.- Sapo de Espuelas (Pelobates cuttripes). Muestreo del 19 de Junio de 1980. 


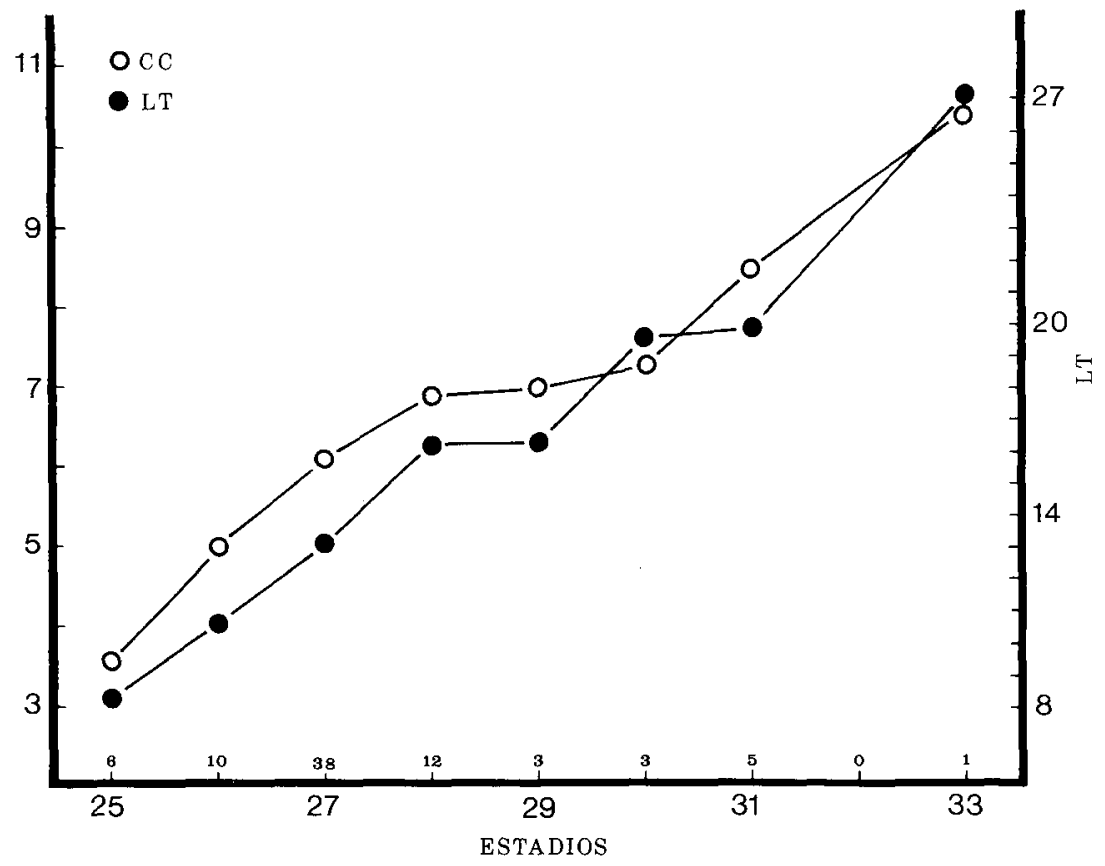

Figura 7.- Ranita de San Antonio (Hyla arborea). Muestreo del 27 de Mayo de 1980.

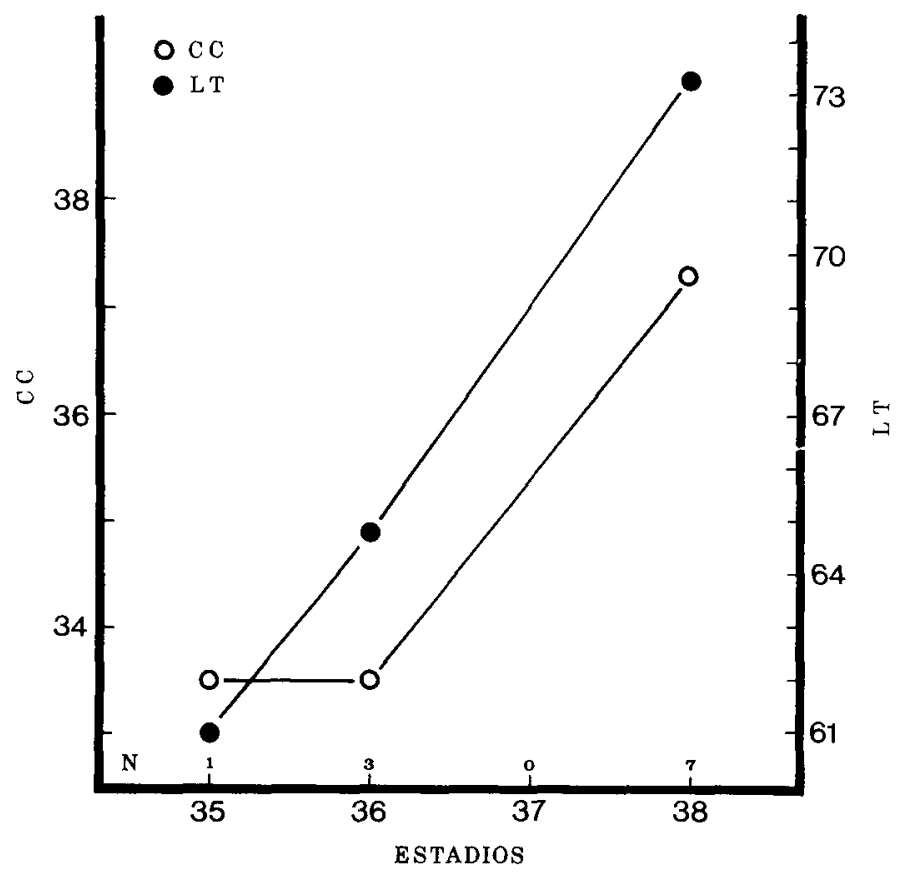

Figura 8.- Ranita de San Antonio (Hyla arborea). Muestreo del 19 de Junio de 1980. 


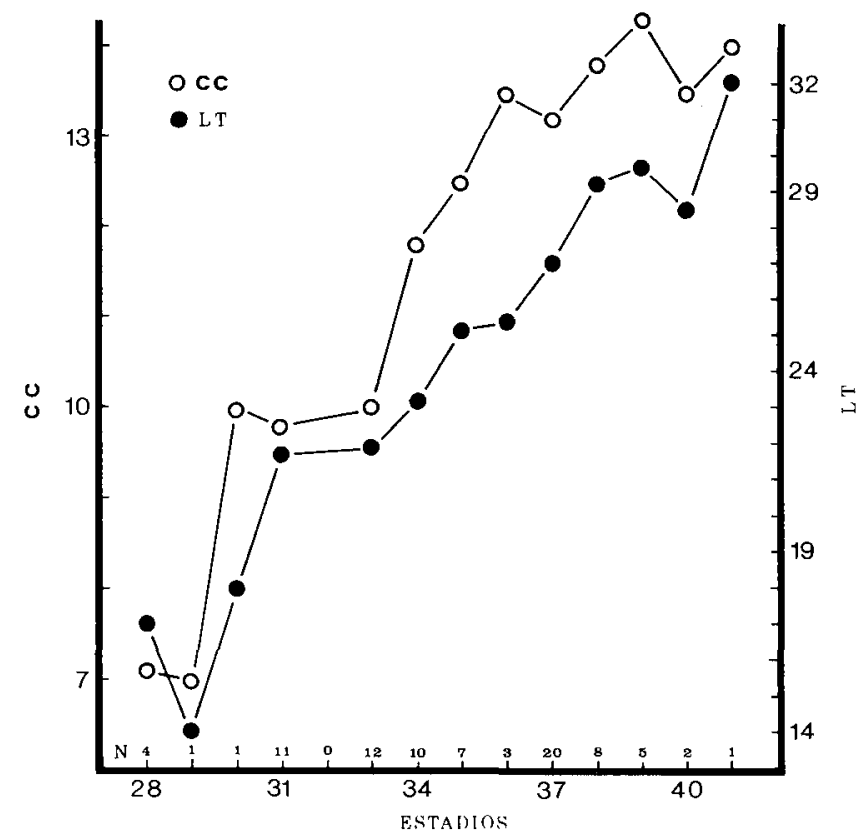

Figura 9.- Ranita de San Antonio (Hyla arborea). Muestreo del 18 de Julio de 1980.

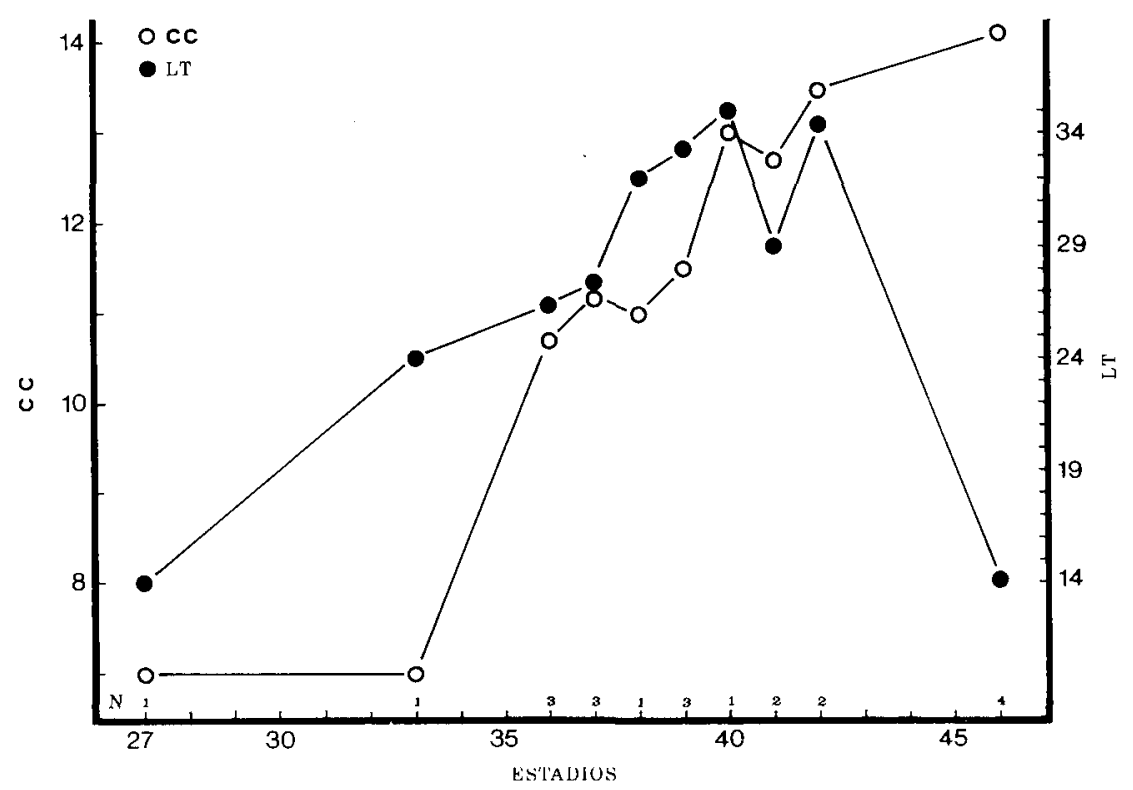

Figura 10.- Ranita de San Antonio (Hvla arborea). Muestreo del 30 de Julio de 1980. 


\section{RANA COMUN, Rana perezi.}

Nuestras primeras observaciones datan del 24 de Febrero, en que se observa gran actividad diurna de jóvenes. Lo mismo podemos decir de las siguientes visitas ( 1 y 15 de Marzo). El 28 de Marzo se ven abundantes jóvenes y adultos activos en los bordes de la laguna de 10 a 13 horas. El día 5 de Abril se oye ya continuo croar de ranas durante el día y el 20 de Abril se constata actividad generalizada de individuos de todas las edades. El 22 de Abril visitamos la laguna a las $21.10 \mathrm{~h}$., siendo todavía de día. En la zona central de la laguna observamos que unos 100 adultos se concentran en un área de unos $25 \mathrm{~m}$. cuadrados. A las $22.45 \mathrm{~h}$. observamos las dos primeras puestas así como dos parejas en amplexus. El 1 de Mayo se encuentran numerosas puestas entre la vegetación del sector pequeño y en menor cantidad en el sector mediano.

Hemos encontrado renacuajos de esta especie en los muestreos del 19 de Junio, 9, 18 y 30 de Julio, 29 de Agosto y 26 de Septiembre. Sólamente tenemos dos renacuajos del 19 de Junio que están en los estadios 29 y 31 . El 9 de Julio obtenemos 48 ejemplares repartidos entre los estadios 28 y 41 , de los que la mayoría se hallan en el 28 al 31 (Figura 11). El 18 de Julio hemos obtenido un total de 101 renacuajos que se distribuyen ampliamente entre los estadios 27 al 42, siendo más abundantes en los estadios inferiores. Los máximos valores de CC y LT aparecen en el estadio 40 de la muestra, con $21.6 \mathrm{~mm}$. y $59.3 \mathrm{~mm}$. respectivamente. También encontramos en esta muestra una disminución de tamaño en los estadios 41 y 42 .

El 30 de Julio se obtienen 103 renacuajos que se reparten desde el estadio 25 al 45 sin solución de continuidad (Figura 12). También aquí los máximos valores se obtienen en el estadio 40 , descendiendo en los siguientes. El 29 de Agosto se han obtenido 73 renacuajos que por un lado repiten la tónica del muestreo anterior con presencia de individuos de la mayoría de los estadios. A diferencia del muestreo anterior, aquí ya hay una proporción destacada de aquellos que ya han terminado la metamorfosis (Figura 13). También difiere del anterior en que el tamaño máximo se alcanza en el estadio 41. Señalamos que el tamaño de las jóvenes ranitas metamorfoseadas es de $24.4 \mathrm{~mm}$. (7 ejs.). También se han estudiado 16 renacuajos recogidos el 26 de Septiembre que pertenecen a un rango estrecho de estadios que van desde el 40 al 46 (Figura 14). La mayoría de ellos han terminado ya la metamorfosis y hay algunos renacuajos de los últimos estadios. Comparando con las ranitas del muestreo anterior desta- 


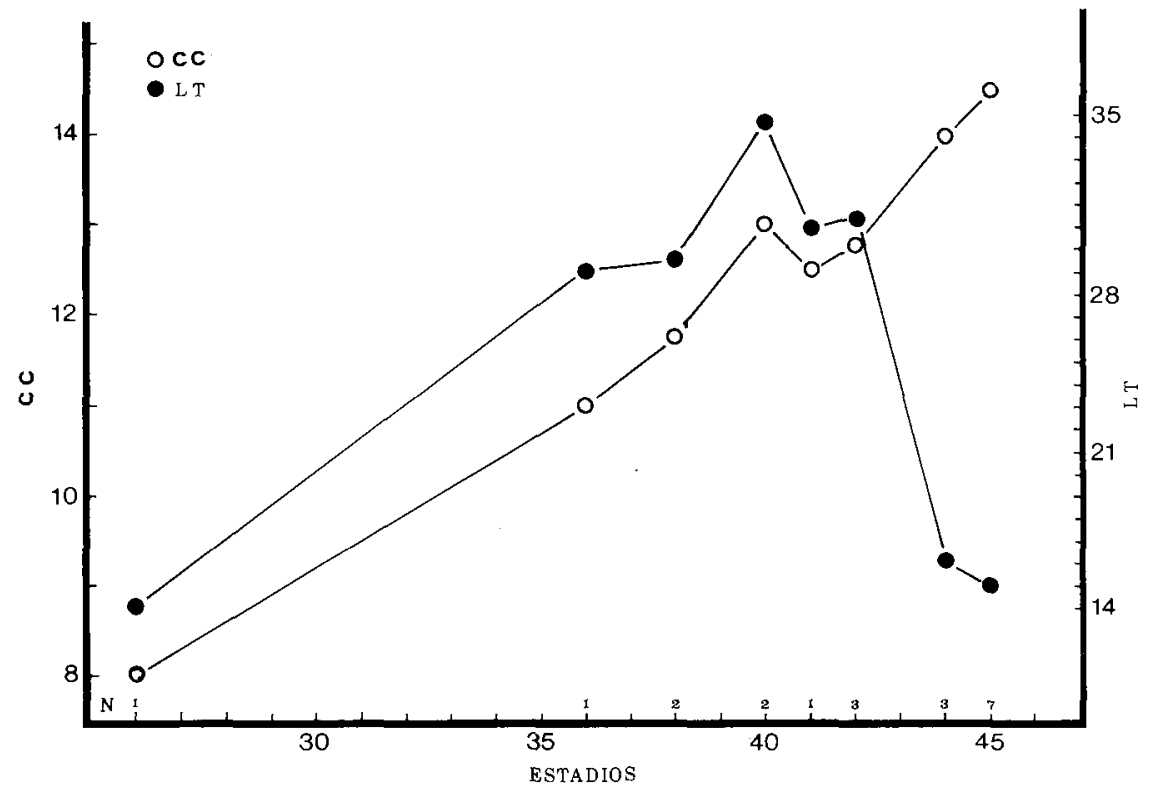

Figura 11.- Rana Común (Rana perezi). Muestreo del 9 de Julio de 1980.

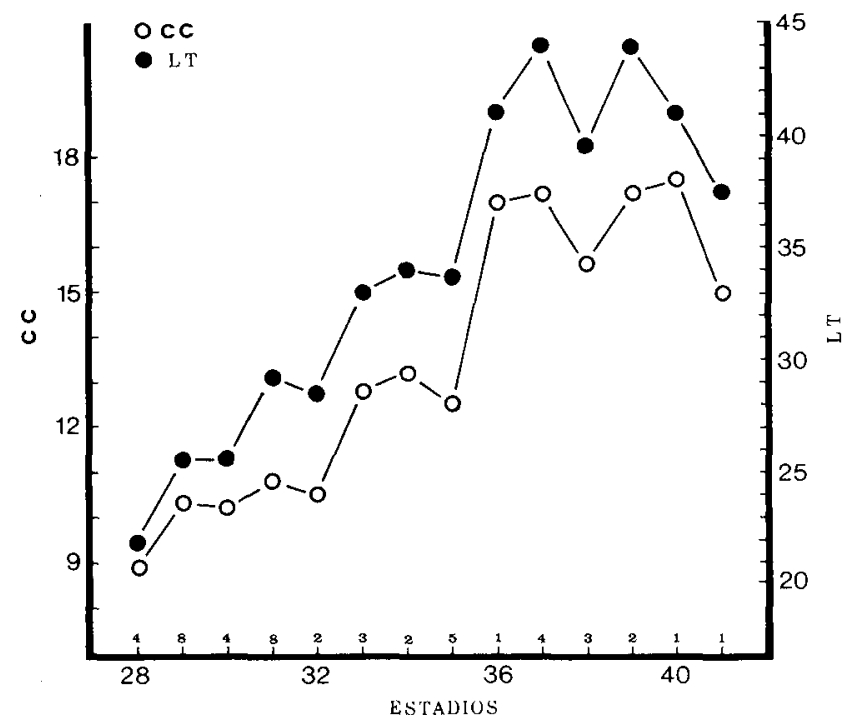

Figura 12.- Rana Común (Rana perezi). Muestreo del 30 de Julio de 1980. 


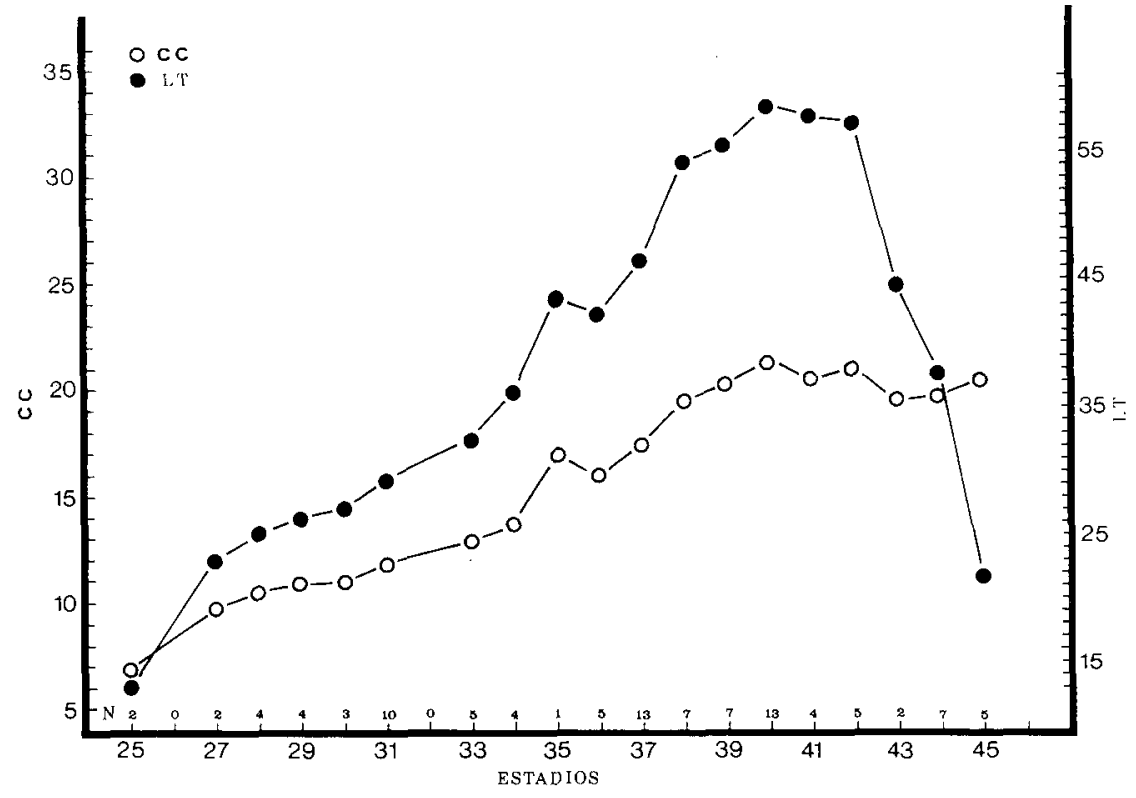

Figura 13.- Rana Común (Rana perezi). Muestreo del 29 de Agosto de 1980.

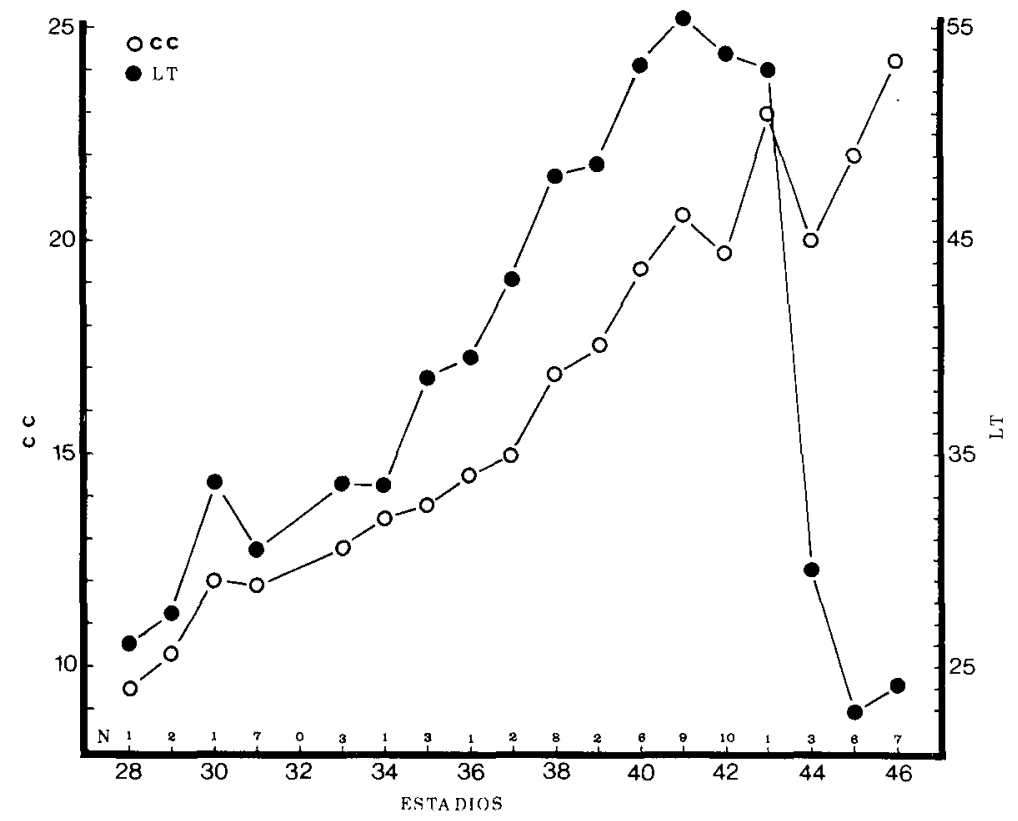

Figura 14.- Rana Común (Rana perezi). Muestreo del 26 de Septiembre de 1980). 
can por su tamaño ligeramente mayor ( $24.5 \mathrm{~mm}$. en 10 ejs.). Finalmente hemos encontrado tres renacuajos invernales el 14 de Noviembre, que se hallan en los estadios 34,35 y 41 y miden de CC $19,18.5$ y $22.5 \mathrm{~mm}$ y 49 , 51.5 y $61 \mathrm{~mm}$. de LT respectivamente. Comparando estos renacuajos con otros del 29 de Agosto correspondientes a sus mismos estadios, vemos que los invernales presentan mayor tamaño.

\section{DISCUSION}

El Sapo Corredor (Bufo calamita) efectúa sus primeras puestas en Chozas a finales de Febrero, comprobándose que éstas se continúan hasta el 10 de Mayo por lo menos. Los primeros nacimientos transcurren después del 12 de Marzo y las primeras metamorfosis tienen lugar a finales de Mayo o principios de Junio. El tamaño que alcanzan los individuos recién metamorfoseados es de 19-11.6 mm. La estación de cría del Sapo Corredor en Inglaterra varía de norte a sur. (Smith, 1973), teniendo lugar la puesta en Edinburgo desde el 6 al 27 de Abril, y en el sur del país en la segunda quincena de Marzo o comienzos de Abril. Nuestros datos de León sugieren que aquí el comienzo de la puesta está algo adelantada. Smith (1973) observó las primeras metamorfosis en Inglaterra el 23 de Mayo y las últimas el 18 de Julio. En Chozas ya han terminado la metamorfosis los más rezagados de 1980 hacia la segunda semana de Junio, pues el día 19 sólo encontramos un renacuajo del estadio 37. Según Smith (1973) la estación de cría es extensa en Inglaterra y se prolonga desde finales de Marzo hasta comienzos de Agosto en años excepcionales. En Holanda (Sparreboom, 1981) la estación de cría se extiende desde mediados de Abril hasta finales de Junio o Julio. En conjunto, la cría en León del Sapo Corredor está algo adelantada.

Los primeros Sapos Corredores abandonan el agua a primeros de Junio en Inglaterra (Smith, 1973), lo que coincide con nuestros datos de Chozas. También en Holanda la metamorfosis tiene lugar en Junio y Julio (Sparreboom, 1981). Cuando abandonan el agua miden 7 a $10 \mathrm{~mm}$. en Inglaterra (Smith, 1973) y 10 a $12 \mathrm{~mm}$. en Holanda (Sparreboom, 1981). Nuestros ejemplares coinciden con los expuestos en su rango de tamaño. Flindt y Hemmer (1972) obtuvieron una puesta en Teruel el 28-29 de Marzo de 1969 que criaron en cautividad llegando a la conclusión de que el desarrollo larvario era similar al estudiado en Alemania (Flindt y Hemmer, 1967, 1970). 
En lo que se refiere al Sapo de Espuelas (Pelobates cultripes), los adultos acuden a las charcas a finales de Febrero o principios de Marzo. Las visitas y estancia de los adultos en los lugares de reproducción se extienden por lo menos hasta finales de Abril. Los primeros renacuajos nacen el 15 de Marzo y no completan su desarrollo hasta la primera semana de Julio. Puestas posteriores completan su desarrollo durante Julio y Agosto.

Busack y Zug (1976) han estudiado la biología del Sapo de Espuelas en Cádiz, aunque sólamente comparan cuatro muestras procedentes de dos localidades y de dos años diferentes. Una de las muestras estudiadas por Busack y Zug (1976) fue recogida en el Puerto de Santa María el 16 de Abril de 1970. En ella los renacuajos se reparten entre los estadios 30 a 44, indicando un período de cría mucho más precoz que en León, donde los renacuajos del 19 de Junio todavía no han pasado del estadio 38 . La muestra del 26 de Abril de 1970 (La Barca de la Florida) reúne renacuajos de estadios 28 al 38. Otra muestra del 20 de Mayo de 1970 (Puerto de Santa María) contiene renacuajos en los estadios 37 al 42. Finalmente, en la muestra del 11 de Mayo de 1969 (Puerto de Santa María) encuentran renacuajos en los estadios 31 al 44 (Busack y Zug, 1976). Si admitimos que la muestra de Chozas de 19 de Junio se corresponde con las puestas más precoces, el retraso con respecto a Cádiz puede ser de unos dos meses.

Las muestras de León presentan mayor variabilidad en las series de dientes que las estudiadas por Busack y Zug en Cádiz. Aunque en renacuajos de estadios 26 y 27 de 12 de Abril hay exclusivamente la fórmula $3 / 5$, en los pertenecientes al 10 de Mayo y que están en los estadios 26 al 29 la situación se modifica. Sigue predominando la fórmula $3 / 5$, pero hay algunos 4/5, 3/4, 2/5 y 4/4. En el muestreo del 27 de Mayo, y con estadios 21 al 31, la fórmula es únicamente 4/5. La misma fórmula aparece en los renacuajos de los estadios 35 al 38 del 19 de Junio. De nuestros datos deducimos que hay variación ontogenética en la fórmula labial del Sapo de Espuelas con aumento inicial y reducción premetamórfica.

Según nuestras observaciones la Ranita de San Antonio (Hyla arborea) acude a la laguna en la primera semana de Abril. Los amplexus y las puestas tienen lugar durante todo el mes de Abril, aunque los machos continúan cantando a primeros de Mayo. Los renacuajos alcanzan una LT media máxima de $37.5 \mathrm{~mm}$. y sufren la metamorfosis en la segunda quincena de Julio. El tamaño medio de CC de las jóvenes ranitas recién meta- 
morfoseadas es de $14.1 \mathrm{~mm}$. Existen pocos antecedentes bibliográficos sobre la biología de la Ranita de San Antonio (Boulenger, 1896-1897) (Schneider, 1977) (Van Gelder et al., 1978 a, 1978 b, 1978 c). En Holanda los machos empiezan a cantar a mediados de Abril y los amplexus tienen lugar en Abril o principios de Mayo (Sparreboom, 1981). En general podemos decir que nuestros datos de León coinciden con los de Europa central. Según Boulenger (1896-1897) los renacuajos de esta especie alcanzan un tamaño máximo de $49 \mathrm{~mm}$. En Chozas hemos encontrado una LT máxima media de $37.5 \mathrm{~mm}$. ( 9 de Julio). En cuanto a la metamorfosis ésta tiene lugar en Europa central (Boulenger, 1896-1897) a finales de Julio o comienzos de Agosto. En cambio en León la metamorfosis se termina en la segunda quincena de Julio, como muestran nuestras visitas y muestreos del 18 y 30 de Julio. En ambas visitas se observaron abundantes ranitas en los prados próximos a la laguna.

Con respecto a la Rana Común (Rana perezi) disponemos de las notas de Balcells (1955) sobre Cataluña y Baleares y el trabajo de Vidal (1966) ralizado en Ibiza. Recientemente Hemmer y Kadel (1981) han estudiado las poblaciones de Mallorca asimilándolas a $R$. perezi. La Rana Común comienza a verse en Chozas a finales de Febrero. En estos primeros días se observa actividad diurna de jóvenes y muy escasos adultos. A finales de Marzo y principios de Abril ya hay gran actividad diaria de adultos. A partir de estos días comienza a incrementarse la actividad nocturna de los adultos, que se hace máxima a finales de Abril. Hacia el 22 de Abril comienzan los amplexus y puestas en la laguna. La mayoría de las puestas tuvieron lugar entre el 22 de Abril y el 1 de Mayo. El desarrollo es muy lento y la metamorfosis tiene lugar entre finales de Julio y finales de Septiembre, aunque hay renacuajos que permanecen en la laguna durante el invierno y no tienen la metamorfosis hasta la primavera siguiente. La LT media máxima que alcanzan los renacuajos es de $59.3 \mathrm{~mm}$., encontrada en ejemplares del estadio 40 del 18 de Julio. El tamaño de las ranas al terminar la metamorfosis es de $24.2 \mathrm{~mm}$. (29 de Agosto) o $24.5 \mathrm{~mm}$. (26 de Septiembre).

Según Vidal (1966) la actividad anual comienza en Ibiza en Febrero y las puestas tienen lugar entre primeros de Abril y principios de Junio. En Barcelona, la puesta tiene lugar a principios de Mayo (Balcells, 1955). Aunque imprecisos, estos datos coinciden en general con los de Chozas, pero son un poco más avanzados. En Ibiza, Vidal (1966) observa ya larvas de $15 \mathrm{~mm}$. como máximo el 16 de Abril, sugiriendo puestas tempranas. 
Según Baicells (1955) la metamorfosis tiene lugar en Barcelona a finales de Agosto y durante Septiembre. Por nuestra parte hemos encontrado en Chozas que ésta se extiende desde finales de Julio a finales de Septiembre. Vidal (1966) señala que en Ibiza los renacuajos de puestas tempranas miden entre 40 y $50 \mathrm{~mm}$. a mediados de Junio e indica que lo más frecuente es que estos procesos pasen el invierno en el agua, no sufriendo metamorfosis hasta el 8-10 de Junio. Vidal (1966), añade que los individuos procedentes de puestas más tardías invernan siempre. Hemmer y Kadel (1981) estudian una muestra de Sant Jordi (Mallorca) recogida el 8 de Abril de 1980, con renacuajos repartidos entre los estadios 27 a 40 . Estos autores también encontraron en la muestra abundantes ranas de 23 a $28 \mathrm{~mm}$. que probablemente se tratara de renacuajos invernales. Llama la atención la abundancia de renacuajos invernales en Baleares, cuyo significado ecológico convendría estudiar más a fondo. Como hipótesis de trabajo sugerimos que allí las ranas están casi restringidas a medios permanentes como son las albercas, circunstancia que favorece el retraso estacional de la metamorfosis.

En las figuras 15,16 y 17 se representan los valores diarios durante 1980 de temperaturas máximas y mínimas, \% de humedad y precipitación recogidos en la Estación Metereológica de la Virgen del Camino (León), distante de Chozas unos $6 \mathrm{~km}$. en línea recta. En conjunto los ciclos de cría de esta comunidad de anuros coinciden con aquellos meses en que hay mayor nivel de precipitación y de humedad relativa, aunque las temperaturas mínimas que se registran a primeros de año con numerosas heladas retrasan el inicio de la cría. Sólamente $R$. perezi amplía su ciclo al verano.

A finales de Febrero comienzan a criar dos especies: Bufo calamita y Pelobates cultripes. En la última semana de Febrero las temperaturas mínimas oscilan entre 6 y $-3.6^{\circ} \mathrm{C}$. En esta semana sólamente hubo 13.2 $\mathrm{mm}$. de précipitación el día 22 . En días anteriores (19 al 21) se registraron precipitaciones que oscilan entre 11.1 y $26.7 \mathrm{~mm}$. Quizás estas lluvias estimulasen el inicio de la puesta en ambas especies y la puesta masiva de $P e$ lobates cultripes del 1 al 7 de Marzo. Un grupo de puestas de $B$. calamita también tuvo lugar esa semana. El otro, más abundante, fue antes del 28 de Marzo, con precipitaciones moderadas durante los días 24 al 28.

Durante los días 12 al 18 de Abril se registraron fuertes lluvias, especialmiente el día $14(60.8 \mathrm{~mm}$.). Ese mismo día se observan las primeras puestas de Hyla arborea. En los días 11 al 16 de Abril las temperaturas 


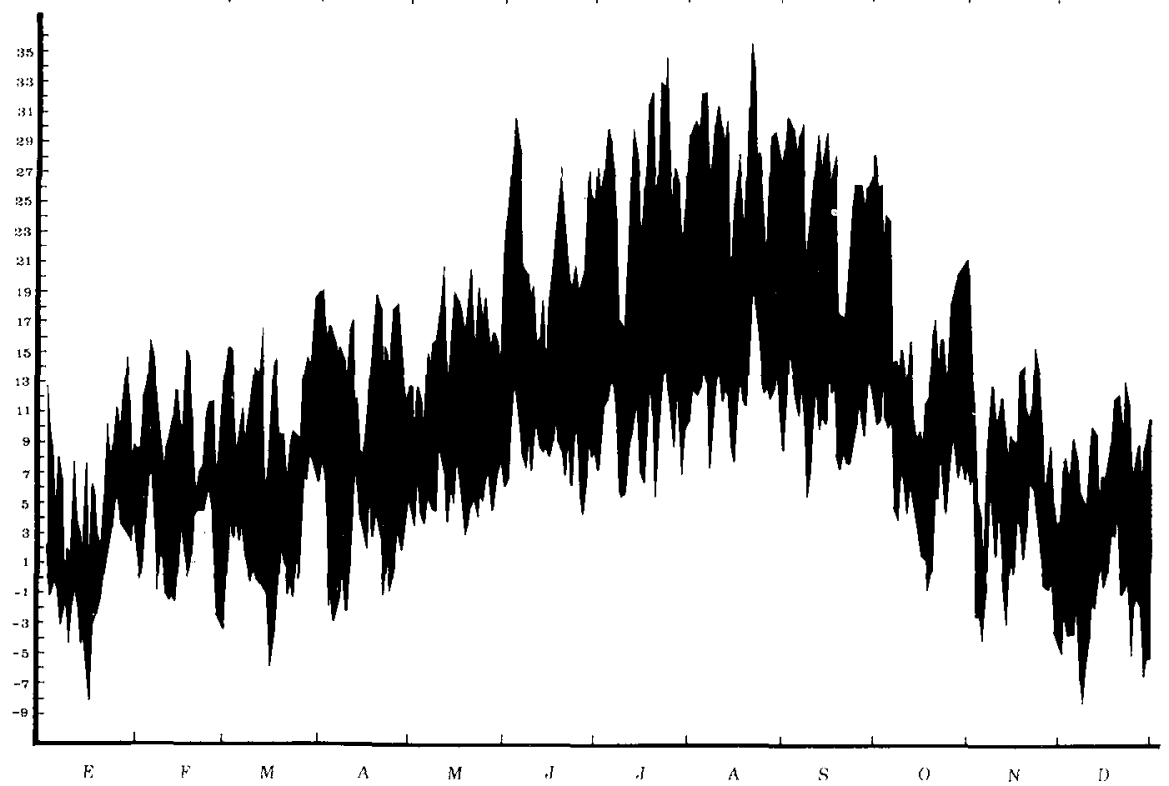

Figura 15.- Temperaturas máximas y minimas durante 1980. Observatorio de la Viruen del Camino (León).

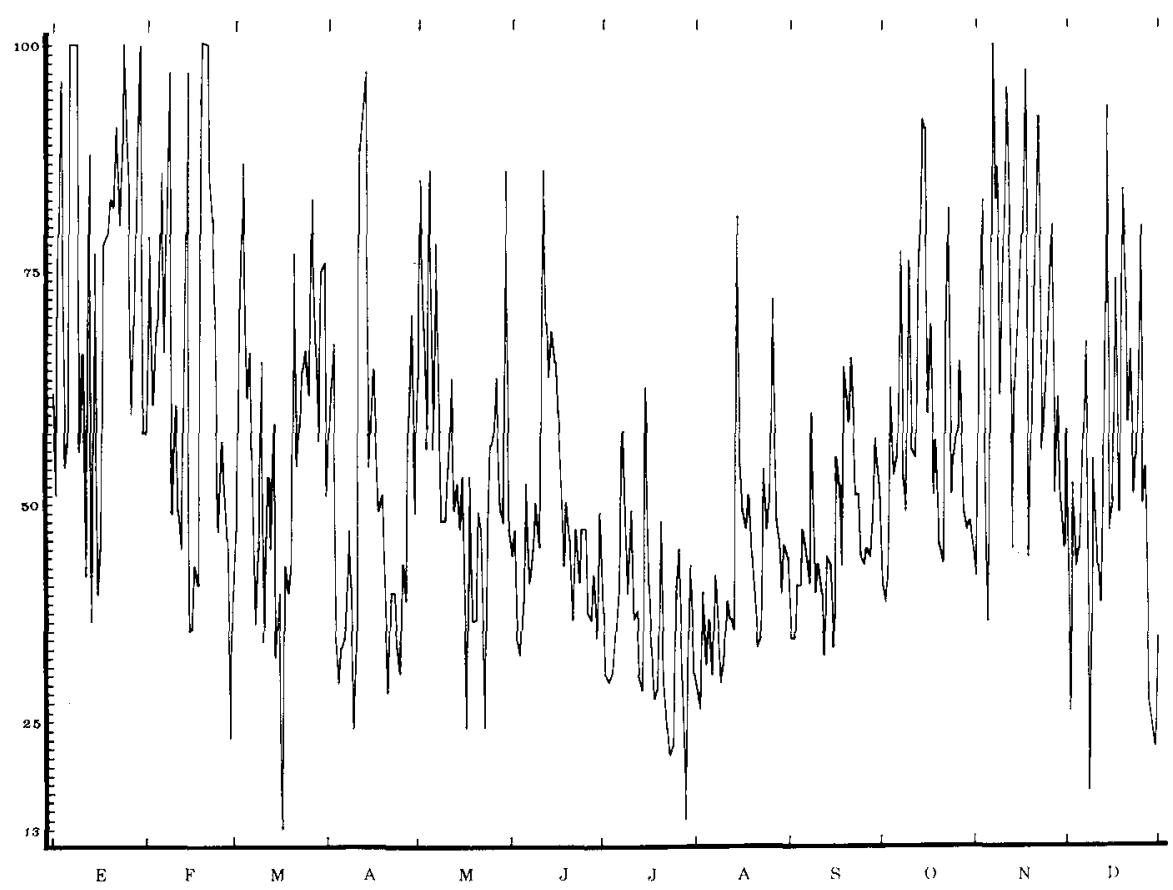

Figura 16.- Humedad relativa durante 1980 en \%. Observatorio de la Virgen del Camino (León). 


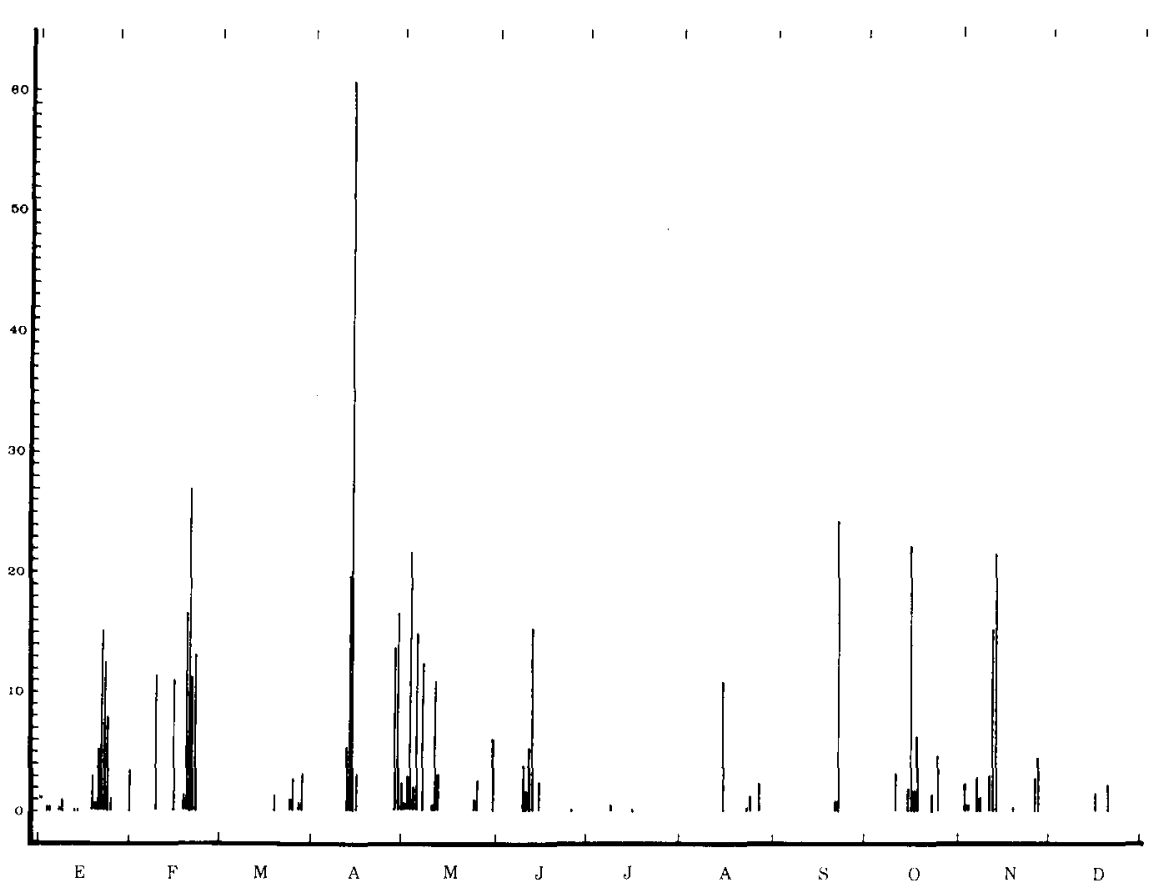

Figura 17.- Precipitaciones diarias en mm. durante 1980. Observatorio de la Virgen del Camino (León).

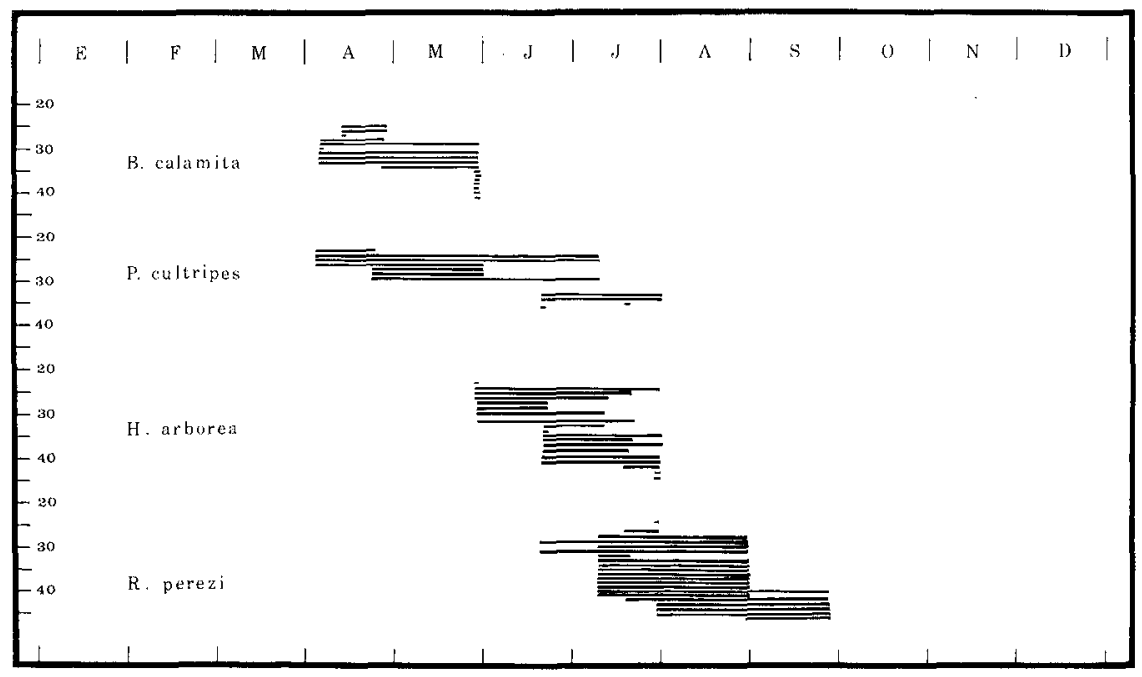

Figura 18.- Comparación de los ciclos de cría de las cuatro especies de anuros a lo largo del año. Las líneas horizontales representan los distintos estadios encontrados para cada especie. 
máximas oscilan entre 8 y $17^{\circ} \mathrm{C}$, mientras que las mínimas lo hacen entre 1.7 y $7.4^{\circ} \mathrm{C}$. El aumento de temperatura es notable, pues en la semana del 4 al 10 de Abril las mínimas oscilaron entre 0.8 y $-3^{\circ} \mathrm{C}$. Durante los días 12 al 14 la humedad relativa osciló entre el 89 y $97 \%$. Hasta el día 22 de Abril no comenzaron las puestas de Rana perezi. Durante los días 15 al 22, las temperaturas máximas oscilan entre 8 y $18.8^{\circ} \mathrm{C}$. y las mínimas entre 6 y $-1.2^{\circ} \mathrm{C}$. No ha habido precipitaciones desde el 15 de Abril y la humedad relativa osciló entre el 28 y el $64 \%$ durante los días 15 al 22 .

A lo largo de nuestro estudio hemos comprobado que hay separación tanto temporal como espacial de las especies que componen la comunidad de cría, aunque el aislamiento no es total y hay un cierto grado de solapamiento entre unas y otras. Las dos primeras especies en criar son B.calamita y $P$. cultripes. La primera hace sus puestas en las orillas o en charcos someros. Sus renacuajos son pequeños, muestran comportamiento de agregación y tienen un desarrollo relativamente rápido. En cambio $P$. cultripes hace sus puestas a mayor profundidad y sus renacuajos son solitarios. También alcanzan gran tamaño y su desarrollo es mucho más lento.

A continuación crían $H$. arborea y $R$. perezi. Ambas efectúan sus puestas en los mismos lugares y sus renacuajos coinciden temporalmente con los de $P$. cultripes. De ellos, los de $P$. cultripes nadan en los lugares abiertos mientras que los de las otras dos especies se ocultan entre la vegetación. También hay grandes diferencias de tamaño entre los renacuajos de $H$. arborea que son pequeños y los grandes tamaños que alcanzan los de $R$. perezi.

\section{BIBLIOGRAFIA}

BALCELLS, E. (1955) Contributions to the study of the life cycle of spanish amphibians Brit. $J$. Herp., 2 (1): 1-6.

BOULENGER, G. A. (1896-1897) The Tailless Batrachians of Europe. 2 vols. Ray Society, London.

BUSACK, S. D. y G. R. ZUG (1976) Observations on the tadpoles of Pelobates cultripes from southern Spain. Herpetologica, 32 (2): 130-137.

FLINDT, R. y H. HEMMER (1967) Okologische und variationsstatistische Untersuchungen an einer Bufo viridis / Bufo calamita population. Zool. Jb. Syst., 94: 162-186. 
FLINDT, R. y H. HEMMER (1970) Vergleichende Untersuchungen Uber das Larval- und Postmetamorphose-Wachstum von Bufo calamita Laur., Bufo viridis Laur. und deren Bastarden. Z. wiss. Zool., 181: 317-330.

FLINDT, R. y H. HEMMER (1972) Studien über die kreuzkrote (Bufo calamita) der Iberischen Halbinsel. Salamandra, 8: 137-151.

HEMMER, H. y B. KADEL (1981) Studien am wasserfrosch - Rana perezi (Seoane, 1885) der Balearen (Amphibia, Anura, Ranidae). Boll. Soc. Hist. Nat. Balears, 24: 55-70.

SCHNEIDER, H. (1977) Acoustic behavior and physiology of vocalization in the European Tree Frog, Hyla arborea (L.). En: The Reproductive biology of amphibians. Taylor, D. H. y S. I. Guttman (eds.). Plenum, New York.

SMITH, M. (1973) The Bristish Amphibians and Reptiles. Collins, London.

SPARREBOOM, M. (ed.) (1981) De Amfibieen en Reptielen van Nederland Belgie en Luxemburg. A. A. Balkema, Rotterdam.

VAN GELDER, J. J., VAN DEN BROEK, J. G. J., STORTELDER, L. J. M. y P. B. KELLENERS (1978) De Boomkikker, Hyla arborea, in Nederland. I. Algemene Biologie. De Levende Natuur, 81: 65-73.

VAN GELDER, J. J., J. G. J. VAN DEN BROEK, L. J. M. STORTELDER y P. B. KELLENERS (1978) De Boomkikker, Hyla arborea, in Nederland. II. Migratie. De Levende Natuur, 81: 200-205.

VAN GELDER, J. J. y J. G. H. M. IEJSINK (1978) De Boomkikker, Hyla arborea, in Nederland. III. Geluidsproduktie. De Levende Natuur, 81: 218-225.

VIDAL, A. (1966) Estudio biológico de las islas Pitiusas: anfibios. P. Inst. Biol. Apl., 40: 81-112. 